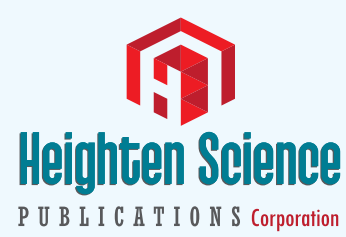

ISSN

2639-9938

\title{
Parental Role in Adolescent Substance Abuse Prevention
}

\author{
Shelby Miller* \\ School of Nursing and Human Physiology, Gonzaga University, USA
}

\begin{abstract}
*Address for Correspondence: Shelby Miller School of Nursing and Human Physiology, Gonzaga University, USA, Tel: 801831 9655; Email: shelbyelainemiller@gmail.com

Submitted: 24 July 2018

Approved: 01 August 2018

Published: 02 August 2018

Copyright: @2018 Miller S. This is an open access article distributed under the Creative Commons Attribution License, which permits unrestricted use, distribution, and reproduction in any medium, provided the original work is properly cited
\end{abstract}

Check for updates

\section{Abstract}

Background: There is a huge gap in the U.S. health care system when it comes to the prevention of substance abuse and addiction, specifically involving adolescents. It has been determined through literature review that parents in Utah are not informed about/knowledgeable of/aware of the current usage of alcohol/ drugs in the adolescent population in this area or the inherent risks involved with consumption/use/misuse/ abuse/addiction.

Aim: The overarching aim of the doctoral project was to prevent Utah County middle school students from harmful alcohol and drug consumption by involving parents in prevention efforts. The prevention goals of this project included: increased parental knowledge of the brain disease of addiction, warning signs of adolescent drug use, what to do if their child is already using, and increased parental self-efficacy on communicating with teens on this subject.

Design: For parents to be productively involved, barriers were broken down through education. The DNP student completed a 15-minute presentation at five separate parent meetings that took place annually during middle school registration at Lehi Jr High.

Population: The education was for parents, foster parents, guardians, etc. of first-year middle school students only; an estimated 420 participants were in attendance.

Data collection and analysis: A pre-and post- combined self-efficacy and knowledge test was given to the attendees. Data was gathered from 117 appropriately completed tests and analyzed using a paired t-test. The results were studied to evaluate effectiveness of the program relating to parental self-efficacy and knowledge.

Findings: The presentation ultimately increased parental self-efficacy and knowledge (p-value <0.01) which in turn increases protective factors and decreases risk factors associated with adolescent substance abuse.

Conclusion: The DNP project was successful, and the results assisted in the refinement of the presentation for sharing on a mass level to all Jr. High schools in Utah County, Utah.

\section{Introduction}

\section{Prevention of substance and alcohol use in adolescents}

There is a huge gap in the U.S. health care system when it comes to the prevention of substance abuse and addiction, specifically when it comes to adolescents. Recently, in the state of Utah there has been a steady and rapid influx of drug and alcohol use, including the adolescent population. According to the [1], from 2000 to 2014, Utah has experienced a nearly $400 \%$ increase in deaths from the misuse and abuse of prescription drugs. Using drugs and alcohol has become expected and accepted in Utah communities, even among those as young as 12 to 15 years old. Since illicit drugs can have long-lasting effects on the developing brain, adolescent substance abuse needs to be identified and addressed as soon as possible [2]. There is significant evidence that parents are unaware of the extent, availability, and riskiness of youth drinking and substance abuse [3]. For example, in a longitudinal survey performed by Bonnie and $0^{\prime}$ Connell parents were asked how often their own child was drinking. In ages 12 to 18 years old, 44 percent of all the youth reporting drinking in the past year were described by their parents as nondrinkers. This study showed that more than half of parents are aware that their child is drinking, and there is a substantial fraction of parents who are not aware even when the child admits to recent heavy drinking. 
These findings supported the need for the scholarly project involving parents of the adolescent population. For example, many parents in the Utah community have expressed complete shock when learning the local popularity of smoking marijuana in $7^{\text {th }}-9^{\text {th }}$ grade. The transition period between grade school and middle school is the time when students are at the highest risk for substance abuse [2]. Currently, the local middle school has no program in place to help parents to increase awareness.

\section{Practice problem and significance to nursing and healthcare}

According to the Substance [4], approximately 2.2 million adolescents aged 12 to 17 in 2015 were current users of illicit drugs, which represents 8.8 percent of adolescents [5]. During the teenage years, adolescents are specifically vulnerable to substance abuse disorders because their brain is still maturing and malleable. This means that teens are highly motivated to pursue pleasurable rewards and avoid pain, however their judgment and decision-making skills are still limited because their prefrontal cortex has not fully matured [2]. Early drug use can be affiliated with other risky behavior including intoxicated driving, unsafe sex, deadly accidents, and other hazardous activities. With repeated use, teens are at risk for impaired memory, failure in school, loss of interest in normal healthy activities, increased risk of contracting infectious diseases such as hepatitis C, mental health problems, and risk of overdose and/or death. This is a national public health issue that needs to be addressed concurrently by parents, school teachers, community leadership, nurses, and other health care providers. Advanced practice nurses are well equipped to help with this prevention problem.

\section{Purpose of the DNP project}

The purpose of the DNP project was to help parents understand the prevalence, risk, and severity of alcohol and drug abuse as their child transitions from elementary school to middle school. The overall goal was to prevent substance and alcohol use in middle school children.

The prevention goals of this project included the following:

1. Teach parents about addiction and the risks of adolescent substance abuse.

2. Teach parents the warning signs of adolescent drug and alcohol use.

3. Provide parents with resources to address current adolescent drug abuse.

4. Enhance self-efficacy of parents about how to have conversations with their child concerning drug and alcohol use.

\section{Social value of proposed DNP project}

Substance abuse and addiction can destroy communities and families. Healthy people 2020 identified a goal to reduce substance abuse to protect the health, safety, and quality of life for all, especially children [6]. Research has shown that as the number of risk factors increase, and the protective factors are reduced, youth in their adolescent years have an increased risk of engaging in substance abuse. Although adolescence is generally a healthy period of life, Healthy people 2020 listed substance use and abuse as a public health and social problem that can start during these years. Healthy people 2020 identified a goal to reduce adolescent substance abuse and listed policies and programs in place to address this health issue [7]. The more a prevention program such as the DNP project decreases risk factors and increases protective factors, the more likely it will be in providing youth with the tools needed to say no to substance abuse.

\section{Methods and Design}

The aim of the scholarly project was to have five successful program presentations during the registration period that takes place every Spring and Summer when 
parents are registering their $7^{\text {th }}$ grader for Jr. High. An overarching goal was to create a successful and sustainable learning program for parents that continues to take place annually. The DNP student created a pamphlet that was also given to all in attendance which covered the following: information on the brain disease of addiction, risk and protective factors of addiction, identifying factors of substance abuse, as well as local and online resources parents can use if they suspect or find their child using drugs. Key informants for this project included the following: parents with students transitioning from elementary school to middle school in the Utah County area, teachers and administrators who work with this age group at the middle school, the principal of the middle school, the school counselors, the PTA director, and the DNP student. The DNP student gained approval from the school administration to conduct the project onsite as well as IRB approval through Gonzaga University.

\section{Population and setting}

Research subjects included all parents of adolescence in attendance at training sessions. All parents in attendance had the opportunity to participate. Any adult (guardian, foster parent, etc.) with custody or influence of a middle-schooler had the opportunity to participate. Only English-speakers and writers were able to participate as there was not interpreters available. Parents/guardians/foster-parents (basically any adult with custody of a first-year middle school student) was required to attend a registration night in order to register their 7th grader for middle school. This registration night was when the DNP project took place. The parents and students separated and while the students were going on a tour of the school, the DNP student gave the 15-minute presentation to the adults only. No advertising or recruitment was needed as it was estimated that 300 500 parents would be in attendance over 5 sessions. Before the DNP student shared the 15-min presentation, parents/guardians/etc. in attendance were asked to voluntarily fill out the optional self-efficacy and knowledge pre-test. After the presentation, the same sample was then asked to fill out the optional post-test. After the registration periods, the project presentation and pamphlet were made available through the school so parents and teachers could access it at any time. The presented and posted information additionally included a list of local detoxification centers, rehabilitation centers, and 12step addiction recovery meeting locations in the valley as well as links to various support meetings and educational websites such as al anon, alcoholics anonymous, heroin addicts anonymous, www.parentsempowered.org, and www.drugabuse.gov.

\section{Data collection and analysis}

There were an estimated 420 attendees combined throughout the five presentations. One pre-and post-combined self-efficacy and knowledge test was given to each attendee. Data was gathered and sorted. 117 attendees appropriately completed the pre- and posttest completely. 24 attendees completed the pre-test only and 38 attendees completed the post-test only. Data gathered from the completed and correctly filled out forms was analyzed using a paired t-test with a repeated measures and one-tail design. Combined self-efficacy scores from the pre-tests and the post-tests were compared.

\section{Findings}

The data from the 117 fully completed pre- and post-tests was found to be highly statistically significant with a p-value of 0.0000000000000000000033 and a confidence interval of $>99.9 \%$. Therefore, the doctoral project presentation significantly increased the measured parental self-efficacy and knowledge. See (Appendix A) for t-test results and graphs representing data distribution comparing combined parental self-efficacy scores before the doctoral presentation (pre-test) and after the doctoral presentation (post-test).

\section{Discussion of findings}

The results from the data analysis and paired t-test were gathered and studied to evaluate the presentation effectiveness on parental self-efficacy and knowledge. 
Overall, the doctoral project presentation produced a significant increase in parental self-efficacy and knowledge. These findings are encouraging and supported the overarching goal of creating an annual teaching program for parents that effectively educates them on adolescent substance abuse.

\section{Conclusion}

The 15-minute educational presentation ultimately increased parental self-efficacy and knowledge which in turn increases protective factors and decreases risk factors associated with adolescent substance abuse. The pre- and post-test also included a small section at the bottom where attendees could write constructive feedback and whether there were any other topics they would have liked addressed. The presentation was then improved and refined for future presentations based upon the data and feedback gathered. For dissemination, the final project presentation and results have been shared with Lehi Jr. High's administrators, counselors, health teachers, and PTA members with the goal of making the information readily available for parents. A poster at a state NP conference in Utah is also planned. Ultimately, a program that educates parents who in turn educates their adolescent about addiction, gateway drugs, and resources for prevention has the potential to save lives. There is potential for this program to be extremely successful and to be repeated annually as long as it is thoughtfully, tactfully, and ethically executed.

\section{References}

1. Utah Department of Health. Prescription drug overdoses. 2014. Ref.: https://tinyurl.com/ybnn7r9f

2. National Institute on Drug Abuse. Principles of adolescent substance use disorder treatment: A research-based guide. 2014. Ref.:https://tinyurl.com/yb3o24o3

3. Bonnie RJ, O'Connell ME. Reducing Underage Drinking: A Collective Responsibility. Washington. The National Academies Press. 2004. Ref.: https://tinyurl.com/y8egb47n

4. Substance Abuse and Mental Health Services Administration (SAMHSA). Behavioral Health Barometer: Utah. 2015.

5. Center for Behavioral Health Statistics and Quality. Key substance use and mental health indicators in the United States: Results from the 2015 National Survey on Drug Use and Health. 2016. Ref.: https://tinyurl.com/6sz7f7y

6. Adolescent Health. 2017. Ref.: https://tinyurl.com/y8bfsj8q

7. Substance Abuse. 2017. Ref.: https://tinyurl.com/nxnva8n 